Document downloaded from:

http://hdl.handle.net/10251/47486

This paper must be cited as:

Martínez Fernández, P.; Villalba Sanchis, I.; Insa Franco, R. (2013). Monitoring and analysis of vibration transmission for various track typologies. A case study. Transportation Research Part D: Transport and Environment. 24:98-109. doi:10.1016/j.trd.2013.05.003.

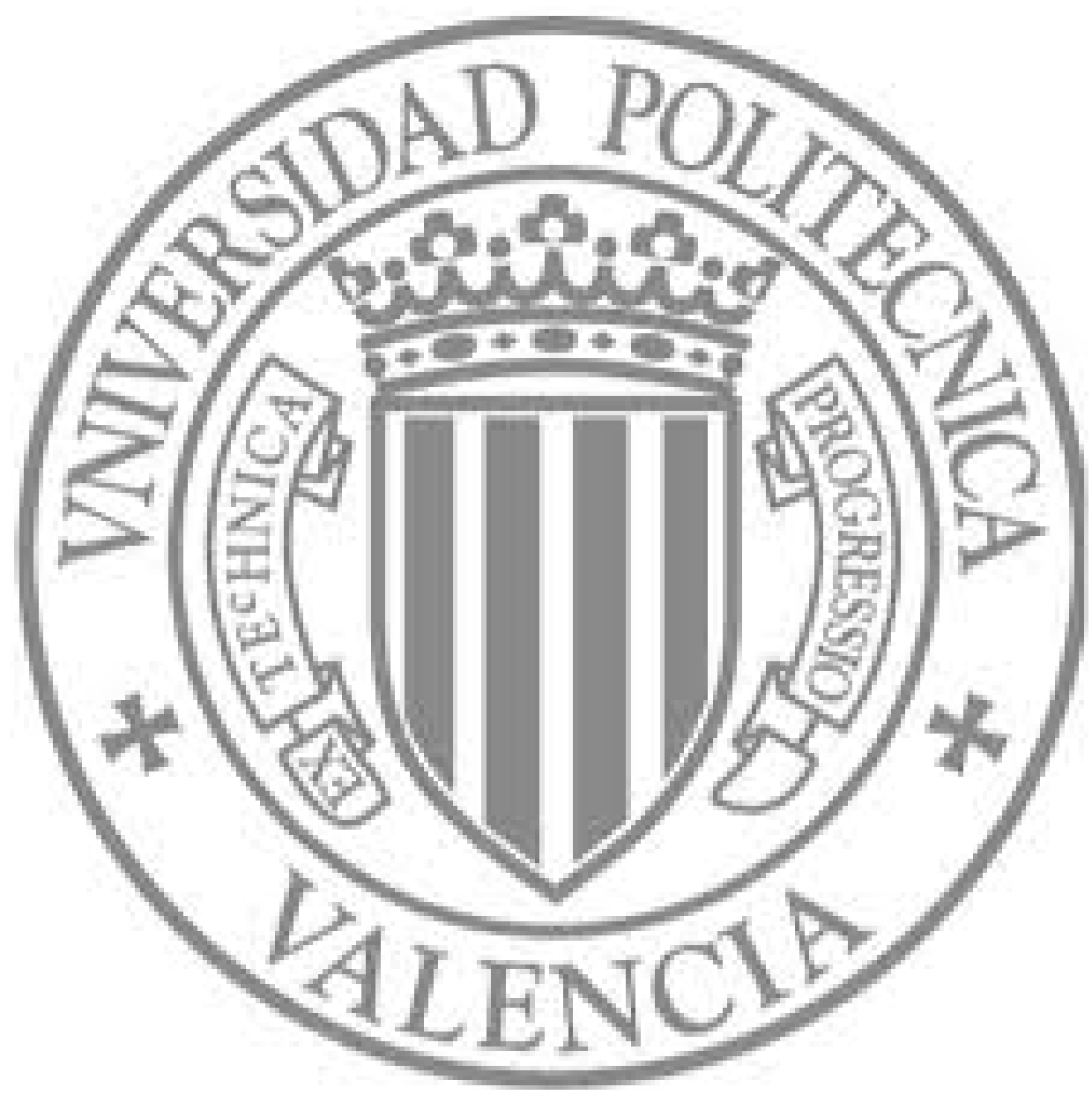

The final publication is available at

http://dx.doi.org/10.1016/j.trd.2013.05.003

Copyright Elsevier 


\title{
MONITORING AND ANALYSIS OF VIBRATION TRANSMISSION FOR VARIOUS TRACK TYPOLOGIES. A CASE STUDY
}

\author{
Pablo Martínez Fernández ${ }^{\mathrm{a}}$, Ignacio Villalba Sanchís ${ }^{\mathrm{a}}$, Faiver Botello Rojas ${ }^{\mathrm{b}}$, \\ Ricardo Insa Franco ${ }^{a} *$ \\ ${ }^{a}$ Department of Transport Engineering and Infrastructure. Universidad Politécnica de \\ Valencia. Camino de Vera, s/n, 46022, Valencia, Spain. \\ ${ }^{b}$ Railways Group. Technological Innovation Directorate. ACCIONA Infraestructuras. \\ Calle Severo Ochoa, 9, 29590, Campanillas, Málaga, Spain.
}

\begin{abstract}
Vibrations propagated from railways can disturb local residents. Within this context, this paper presents a monitoring exercise involving diverse track typologies, ranging from tram slab tracks to high-speed ballasted tracks. The results show a slightly better performance of ballasted tracks when dealing with low frequency vibrations, and an overall similar alleviation pattern for the whole bandwidth. Other issues such as vehicle influence and vibration of sleepers are discussed.
\end{abstract}

Keywords: Railways, Metro, Tram, vibration, spectra, mitigation

\section{Introduction}

Railways pose a number of environmental challenges including those associated with noise and vibration. Vibrations transmitted through the track into the ground can affect the foundations of nearby buildings and annoy inhabitants, not only as vibration per se, but as a source of structural noise. Additionally, vibration within the track can increase wear on such things as sleepers, pads, and fastenings.

Here we examine vibrations associated with various track typologies, ranging from slab to ballasted tracks and from trams and metros to high-speed trains. We examine vibration levels of different elements of each track. This is used to determine vibration trends and to assess the performance of each typology in terms of vibration generation, transmission and alleviation.

Vibrations are a form of energy transmission, a mechanical wave travelling through a physical medium. Sound is a particular case of such vibration; a wave transmitted through air with frequencies within the range of hearing. In the case of railways, sound propagation has been extensively studied but vibration transmitted through the track and the ground less so and usually as a secondary phenomenon. Piezoelectric sensors are used, because they provide a consistent and cost-effective monitoring solution, to look at the latter.

\section{Methodology}

Up to six sections of track were monitored, including ballasted and slab tracks, trams, metros and high-speed lines. Most of them correspond to the tram and metro network

* Corresponding author: rinsa@tra.upv.es 
operated by FGV in Valencia (Spain), including part of the surface lines that provides a commuter service between Valencia and its metropolitan area.

The first section (A) is a tram slab track with type Phoenix RI-60 rails embedded in elastomer. The slab is $26 \mathrm{~cm}$ thick and made of reinforced concrete, supported by a 25 $\mathrm{cm}$ layer of gravel. Over the slab is a $12 \mathrm{~cm}$ layer of paving stone. This track typology is found in the tram network of Valencia used by light series 3800 (SIEMENS) and 4200 (BOMBARDIER) rolling stock of seven to ten tonnes per axis and with an average speed of 30 to $40 \mathrm{~km} / \mathrm{h}$. Section (B) is a metro slab track found on Line 1 of the Valencia metro network. It is a STEDEF slab track made of UIC54 rails resting over pads and concrete plugs with elastomeric soles resting directly on the slabs. The rolling stock consists of series 4300 (VOSSLOH) with an average weight of 11 tonnes/axis, traveling at an average speed of $30 \mathrm{~km} / \mathrm{h}$.

Sections C1, C2 and C3 are Metro ballasted track comprising UIC54 rails over pre-stressed concrete, monobloc, sleepers, a clip fastening system and a $70 \mathrm{~cm}$ ballast layer. The rolling stock is the same as for Section B. Three sections were monitored after initial measurements showed peaks of acceleration exceeding expectation; two additional sections were monitored together with the original to check the reliability of the data. The average speed for sections $\mathrm{C} 1$ and $\mathrm{C} 2$ is between $60-70 \mathrm{~km} / \mathrm{h}$ and $30 \mathrm{~km} / \mathrm{h}$ for C3.

The fourth section (D) is a high-speed ballasted track from the Madrid-Valencia High Speed line, operated by RENFE. It consists of UIC60 rails over pre-stressed concrete monobloc sleepers, clip fastening system and a $75 \mathrm{~cm}$ ballast layer. The track is $1435 \mathrm{~mm}$ (international) gauge and the rolling stock consists of AVE series 112 and ALVIA series 130 trains, with the former running at $300 \mathrm{~km} / \mathrm{h}$ and the latter at $250 \mathrm{~km} / \mathrm{h}$.

The sections were monitored using uniaxial piezoelectric accelerometers to record the vertical vibration generated by the passing of trains and its transmission through the infrastructure into the ground. Accelerometers were attached to the surface of rails, sleepers, etc., and connected to a four-channel signal conditioner, which in turn was connected to a laptop to store the data. In every ballasted track section, accelerometers were placed in sleeper, ballast and ground (the latter by means of a buried pick). Additionally, rail vibration was also measured in sections C1, C2 and C3. For slab tracks, accelerometers were placed at distances from the rail, as well as in the sleeper in section B. An outline of the accelerometers placing is shown in Figure 1.

Once the accelerometers were installed, each section was monitored during a single day, recording between eight and 20 trains. Measurements were made at a sampling frequency of $2048 \mathrm{~Hz}$ and a high pass filter of $0.7 \mathrm{~Hz}$. Additionally, velocity of the trains was also measured, either directly by means of a GPS system on board or estimated by measuring the time of passing between two catenary pylons ${ }^{1}$.

\footnotetext{
${ }^{1}$ Raw data were converted to UFF format and loaded into Mathematica 7.0 (Wolfram Research, Inc.) for post-processing. By means of a discrete Fourier transformation, acceleration spectra were obtained for each
} 
Two models are used to assess the typologies. The first is a $2 \mathrm{D}$ analytical model based on the wave equation.

$(\hat{\lambda}+\hat{p}) v_{x z}\left(v_{x z}[u\}\right)+\hat{\mu} v_{x z}^{2}\{u\}=\rho \frac{\partial^{2}\{u\}}{\partial t^{2}}$

Where $\{u\}$ is the displacement vector, $x$ is the horizontal dimension (parallel to the track), $z$ is the vertical dimension (positive downwards), $t$ represents time and $\rho$ represents density. Operators $\hat{\hat{\lambda}}$ and $\hat{\mu}$ are defined as:

$\hat{\lambda}=\lambda+\lambda^{*} \frac{a}{\partial t}$

$\hat{\mu}=\mu+\mu^{*} \frac{\partial}{\partial t}$

Where $(\lambda, \mu)$ are the Lamé parameters which represent the elastic behaviour of the materials, while $(\lambda *, \mu *)$ are damping coefficients for the viscous behaviour.

The track is modelled as a three layered, 2D space, the lower layer being a Boussinesq half-space, i.e. a layer which has no lower limit but extends infinitely, thus making sure that waves traveling down the ground are attenuated and not reflected back to the track.

Each layer corresponds to a different track component (sleeper, ballast, ground, etc.) the vibration of which is determined by equation 1 . The rail is modelled as a Timoshenko beam allowing both bending and shear deformation to be considered. The load applied is obtained from an auxiliary quarter car model (Melis 2008) moving along a deformed rail. This takes into account both the static load (the train weight) and the dynamic components (load variations due to rail irregularities).

To solve equation 1, a Fourier transformation is applied to shift from the time and space domain to that of frequency and wave number.

$\mathrm{f}(\mathrm{k}, \mathrm{z}, \omega)=\int_{-\mathrm{z}}^{m} \int_{-\mathrm{s}}^{m} \mathrm{f}(\mathrm{x}, \mathrm{z}, \mathrm{t}) \mathrm{e}^{\mathrm{i}(\omega \mathrm{st}-\mathrm{kt})} \mathrm{dxdt}$

where $(\mathrm{k}, \omega)$ are wave number and frequency. Therefore equation 1 becomes a system of two ordinary differential equations.

$\left.\begin{array}{l}\frac{\mathrm{d}^{2} \bar{\psi}}{\mathrm{d} z^{2}}-\mathrm{R}_{\mathrm{L}}^{2} \tilde{\phi}=0 \\ \frac{\mathrm{d}^{2} \psi}{\mathrm{d} z^{2}}-\mathrm{R}_{\mathrm{T}}^{2} \tilde{\Psi}=0\end{array}\right\}$

where $\mathrm{R}_{\mathrm{L}}$ and $\mathrm{R}_{\mathrm{T}}$ are the longitudinal and transversal wave speeds, and $\varphi$ and $\psi$ are a scalar and vector functions of $(\mathrm{x}, \mathrm{z}, \mathrm{t})$, known as the Lamé potentials. The solution for equation 5 is shifted back to the time domain by means of an inverse Fourier transformation, hence yielding horizontal and vertical displacements. The displacementbased equations are then differentiated twice to obtain acceleration.

This model was implemented in Mathematica 7.0 (Wolfram Research, Inc.) and provides a fast, first estimation of vibration levels at locations beyond the limits of the data gathered (see, Salvador et al., 2011; Real et al., 2011).

data set. A $1 \mathrm{~Hz}$ high-pass filter was applied to obtain cleaner accelerographs and 1/3-octave spectra for each data set. Average spectra were calculated for each sensor/location in every section. 
The second model used is a 3D finite elements model (FEM) of each track typology, implemented in ANSYS 13.0 (Ansys Inc.). The purpose of this model is to provide a deeper and more reliable insight of the vibration of the infrastructure, particularly of those elements that are beyond the scope of the analytical model. For each track typology a mesh of hexahedra elements was developed, representing the layers and elements. Each hexahedron has 20 nodes of calculation. Symmetry conditions were considered so as to reduce the model size and reduce calculation time. The track longitudinal axis was taken as axis of symmetry, hence modelling only half of the track (one rail, half sleeper, etc.). Boundary conditions were applied according to the recommendations issued by the Spanish Ministry of Public Works (1999): All displacements perpendicular to each boundary plane were restrained.

Regarding the model loads, they are applied as point loads moving along the track, with each load representing a half axle due to symmetry. For each step of calculation, the load was distributed to the two nearest nodes proportionally to the distance to each. Simulations are conducted for each track typology with different loads and train speeds producing acceleration levels at any desired location.

Measured accelerographs were compared to modelled ones using part of the available data set, fitting acceleration peaks and average levels so as to calibrate the models' damping coefficients $(\lambda *$ and $\mu *$ for the analytical model and Rayleigh's $\beta$ for the numerical model). Calibrated models are then compared to additional data sets for validation. The analytical model showed a good agreement with measurements both for peak values and secondary vibration caused by rail irregularities. The numerical model did not offer such a good fit with the data because it does not take into account rail defects, but it predicted vibration peaks and their distribution accurately.

\section{Results}

Firstly, calculating the average 1/3-octave for each sensor/location within the track allows assessment of vibration alleviation of each section. Maximum acceleration peaks are also compared.

Starting with Section A, sensors were placed in the paving at 15 (S1) and $75 \mathrm{~cm}$

(S2) from the rail. The mean maximum values of acceleration are $23.22 \mathrm{~m} / \mathrm{s}^{2}$ and 2.16 $\mathrm{m} / \mathrm{s}^{2}$, hence giving a tenfold reduction after just $60 \mathrm{~cm}$ of concrete and paving stone. Moreover, the analytical model gives a peak of $3 \mathrm{~m} / \mathrm{s}^{2}$ in the elastomer right under the rail and only $0.73 \mathrm{~m} / \mathrm{s}^{2}$ in the concrete slab beneath the elastomer, which yields a $24 \%$ reduction below the track thanks only to the elastic embedment.

Figure 2 shows the average spectra at both locations - Figure 2 top refers to S1 and bottom to S2. The spectrum closer to the rail - Figure 2 top - shows a clear peak around the $125 \mathrm{~Hz}$ band and noticeable amplitude in the range of 63 to $400 \mathrm{~Hz}$. There is also a small peak at $1.25 \mathrm{~Hz}$. As the wave moves away from the rail through the slab, higher frequencies are clearly alleviated, thus explaining the net reduction of acceleration peaks. Particularly the bands of 100,125 and $160 \mathrm{~Hz}$ have been greatly reduced between S1 and 
S2. Lower frequencies, on the other hand, still remain the same or have even increased slightly. These are of particular interest as low frequency vibrations are the more disturbing for people.

Section B was monitored at the sleeper (S1) as well as at two locations of the concrete slab (S2 and S3). The mean maximum peaks recorded were 29.31, 1.43, and $0.76 \mathrm{~m} / \mathrm{s}^{2}$. This yields an even higher mitigation than that observed in Section A as the wave moves away from the track, which may be due to the elastic sole of the concrete plugs.

When looking at the spectra (Figure 3), that of the sleeper (top), S1, shows two distinctive vibration patterns; one at low frequency $(1.25 \mathrm{~Hz}$ band) and another at between 40 a $500 \mathrm{~Hz}$ with clear peaks in the 160 to $200 \mathrm{~Hz}$ bands. That second pattern almost disappears when looking at the two spectra in the slab, while the peaks at low frequency remain and even increase as observed in Section A. It seems that these low frequency components are affected neither by the elastic sole nor by a rather stiff material such as concrete.

Section $\mathrm{C}$ was monitored in the rail, sleeper and ballast at three locations along the same line; $\mathrm{C} 1$ and $\mathrm{C} 2$ are straight stretches and_C3 is in the middle of a bridge span (Table 1.)

Table 1. Average maximum acceleration peaks in sections $\left(\mathrm{m} / \mathrm{s}^{2}\right)$.

\begin{tabular}{cccc}
\hline Section & Rail & Sleeper & Ballast \\
C1 & 104.47 & 34.68 & - \\
C2 & 168.02 & 32.38 & 3.44 \\
C3 & 48.40 & 20.02 & 3.36 \\
\hline
\end{tabular}

Some measurements were initially taken in a sleeper very close to that of section $\mathrm{C} 1$ and peaks up to $60 \mathrm{~m} / \mathrm{s}^{2}$ were recorded. These results, together with the peaks already measured at the high speed lines (which showed rather small levels of vibration at the sleeper) encouraged the decision of monitor additional sections for this typology. As shown in Table 1, levels at the sleeper are actually about $30 \mathrm{~m} / \mathrm{s}^{2}$ and thus that initial value was thought to be due to a damaged or badly supported sleeper.

In any case, the mitigation pattern from rail to ballast is somehow irregular for this typology. In the first section (C1) there is a $70 \%$ reduction from rail (S1) to sleeper (S2). In C2 the peak in the rail is the highest recorded during the survey, but the level in the sleeper is similar to that in C1 (i.e. an $80 \%$ reduction). Finally, the levels in C3 are clearly lower due to the reduced speed of the trains at that section compared to $\mathrm{C} 1$ and $\mathrm{C} 2$ $(60 \mathrm{~km} / \mathrm{h}$ vs. $30 \mathrm{~km} / \mathrm{h}$ on average). These heterogeneous results suggest that the behaviour of a ballasted track compared to a slab track is much more unpredictable in terms of vibration transmission, although the degree of maintenance of each of the lines surveyed might be also a factor to be taken into account. 
When looking at the rail spectrum from section C1 - Figure 4 top, the main peaks appear at the $315-1000 \mathrm{~Hz}$ band, reaching the maximum at $800 \mathrm{~Hz}$. Lower frequency peaks are comparatively low, although they reach levels similar to those observed at section B. The sleeper spectrum - Figure 4 middle - that refers to S2) shows an overall mitigation in the whole bandwidth. The main peak at $800 \mathrm{~Hz}$ has been greatly reduced, while the band at $630 \mathrm{~Hz}$ is less affected. The peaks in the low frequency band show a twofold reduction.

The spectra in section C2 (Figure 5) present a similar pattern in the rail - Figure 5 top - and the sleeper - Figure 5 bottom. However, in this case the maximum peak appears around $400 \mathrm{~Hz}$ and yields amplitudes three times higher. The whole bandwidth is alleviated in the sleeper, and further mitigation is observed in the ballast - Figure 5 bottom. However, in this last step both peaks around $400 \mathrm{~Hz}$ and low frequency peaks are greatly reduced, whereas a band between 31.5 and $80 \mathrm{~Hz}$ shows a lower decrease.

Section C3 spectra (Figure 6) show an overall lower level of amplitude as expected due to lower average speed. There are two distinctive peaks, one around $63 \mathrm{~Hz}$ and the other around $800 \mathrm{~Hz}$. The amplitude at low frequency $(1.25 \mathrm{~Hz}$ band) is very low. In the sleeper Figure 6 middle - the $800 \mathrm{~Hz}$ band is greatly reduced while the $63 \mathrm{~Hz}$ band is much less alleviated. In the ballast - Figure 6 bottom- the levels are quite low in the whole bandwidth (and similar to those observed in $\mathrm{C} 2$ ballast) although the clearer peaks are still at the $63-160 \mathrm{~Hz}$ band.

Overall the patterns of vibration mitigation observed for each of the C-sections remain irregular. This track, when compared to slab tracks, performs slightly better when alleviating low frequency bands of the spectrum. Comparatively, higher frequency bands are similarly reduced in both slab and ballasted typologies.

Section D was monitored in the sleeper (S1), ballast (S2) and ground (S3). The mean peaks were $18.6,2.6$, and $0.42 \mathrm{~m} / \mathrm{s}^{2}$. Additionally, a peak of $160.1 \mathrm{~m} / \mathrm{s}^{2}$ was obtained from the FEM model in the rail. This yields a rough tenfold alleviation pattern from rail to sleeper, ballast and ground.

The spectrum at the sleeper - Figure 7 top - shows more components when compared to those of the previous sections. There is a distinctive peak at the $1.25-1.6 \mathrm{~Hz}$ band and another at the $31.5 \mathrm{~Hz}$ band, but there is a noticeable level of amplitude right up to the $800 \mathrm{~Hz}$. The whole spectrum is greatly reduced in ballast - Figure 7 middle. The peak at $31.5 \mathrm{~Hz}$ is fully mitigated, and the amplitude is greatly decreased in the $8-50 \mathrm{~Hz}$ band as well as over $200 \mathrm{~Hz}$. There is a lesser-reduced band between 63 and $160 \mathrm{~Hz}$, and the low frequency components are only slightly mitigated when compared to those of the sleeper.

The average spectrum measured at the ground - Figure 8 bottom - follows the same pattern of mitigation. Those frequencies beyond $200 \mathrm{~Hz}$ have been reduced almost entirely, and the $63-160 \mathrm{~Hz}$ band is now almost at the same level as the $8-50 \mathrm{~Hz}$ band. The peak at $1.25 \mathrm{~Hz}$, although being the only clear peak remaining, has been severely reduced, 
thus supporting the suggestion of ballasted tracks performing better with lower frequency vibrations.

In terms of vibration assessment for the sections monitored, we look at the influence of the rolling stock in the vibration spectrum generated because there are different train types passing over each of the typologies studies. Considering section A, Figure 8 shows the mean spectrum for each tram model measured at the spot closest to the rail (S1). Both spectra show almost the same pattern of vibration, and the only apparent difference is a slightly higher peak at $125 \mathrm{~Hz}$ for the 3800 series.

The same comparison is made in Figure 9 for the high-speed trains in section D (S1). Differences appear because AVE trains create higher amplitudes of vibration around the $31.5 \mathrm{~Hz}$ band while ALVIA trains' higher peaks are located in the lowest frequency bands. This variance may be due to the diverse axis structure and damping system of each train type, as well as the dissimilar speed. In any case is a difference noticeable enough to be taken into account when assessing the vibration induced in the track.

In terms of the level of vibration in the sleeper at the ballasted tracks, as the D section corresponds to a High-Speed line, one would expect overall higher values of acceleration than those measured in a metro line because the rolling stock is heavier and faster than in $\mathrm{C} 1, \mathrm{C} 2$ and C3. However, while acceleration levels in the rail and the ballast are quite similar, sleepers in $\mathrm{C}$-sections show greater peaks of acceleration. These results may be due to softer pads in the High-Speed section, as those tend to isolate the sleeper from the rail (hence reducing vibration in the former and increasing it in the latter (Thompson, 2009). However, as vibration levels in the rail are quite similar, other factors should be considered. One of them is maintenance, as the D-section corresponds to a much newer and more maintained line. Therefore, sections $\mathrm{C}$ may present a poorer sleeper support which could increase local vibration.

\section{Conclusions}

When comparing the performance of slab and ballasted typologies for metro lines, it seems that both of them alleviate acceleration peaks at roughly the same pattern. However, after analysing the spectra, ballasted tracks tends to perform slightly better when dealing with the lowest frequency bands. This is of relevance because, according to the ISO standards regarding human exposure to vibration, lower frequencies disturb people most. A ballasted track may thus be a better choice for vibration alleviation than the slab typology, although the latter has other advantages for urban use, especially if their low frequency vibrations are contained by additional alleviation measures.

There is no noticeable difference in vibration patterns between vehicles in the metro lines. This is not the case with high-speed line, although the differences between the ALVIA and AVE trains are relatively small, and likely caused by factors such as axis structure and damping, although because trains running on the same line tend to be 
similar in weight and structure, it can be argued that speed is the main factor to be taken into account, as demonstrated in the AVE/ALVIA case.

Finally, higher levels of vibrations are found in commuter sleepers compared to those used for high-speed lines. This suggests that the vibration of a particular element of the track may be quite unpredictable even if the overall pattern from rail to ground nearby is known. It emerges that there are factors such as pad stiffness, sleeper support and track maintenance which can have a great influence in the vibration of sleepers, and thus in their long term durability.

\section{Acknowledgments}

The authors wish to thank ACCIONA for providing the equipment for the survey, as well as for their help and support during the whole monitoring process. The authors are also grateful to FGV, ADIF and RENFE for providing permission and support during the monitoring of their lines.

\section{References}

Ansys Inc., 2010, ANSYS [Software], version 13.0, Canonsburg, Pennsylvania, USA.

Melis, M. 2008. Introducción a la Dinámica Vertical de la Vía y Señales Digitales en Ferrocarriles (Introduction to Track Vertical Dynamics and Railway Digital Signals). UPM, Madrid.

Real, J., Martínez, P., Montalbán, L., Villanueva, A. 2011. Modelling vibrations caused by tram movement on slab track line, Mathematical and Computer Modelling 54, 280-291.

Salvador, P., Real, J., Zamorano, C., Villanueva, A. 2011. A procedure for the evaluation of vibrations induced by the passing of a train and its application to real railway traffic, Mathematical and Computer Modelling 53, 42-54.

Spanish Ministry of Public Works. 1999. Recomendaciones para el proyecto de plataformas ferroviarias (Recommendations for the design of railway platforms). Centro de Publicaciones del Ministerio de Fomento, Madrid.

Thompson, D. J. 2009. Railway Noise and Vibration: Mechanisms, Modelling and Means of control. Elsevier, Oxford.

Wolfram Research Inc., 2008. Mathematica [Software], version 7.0, Champaign, USA. 


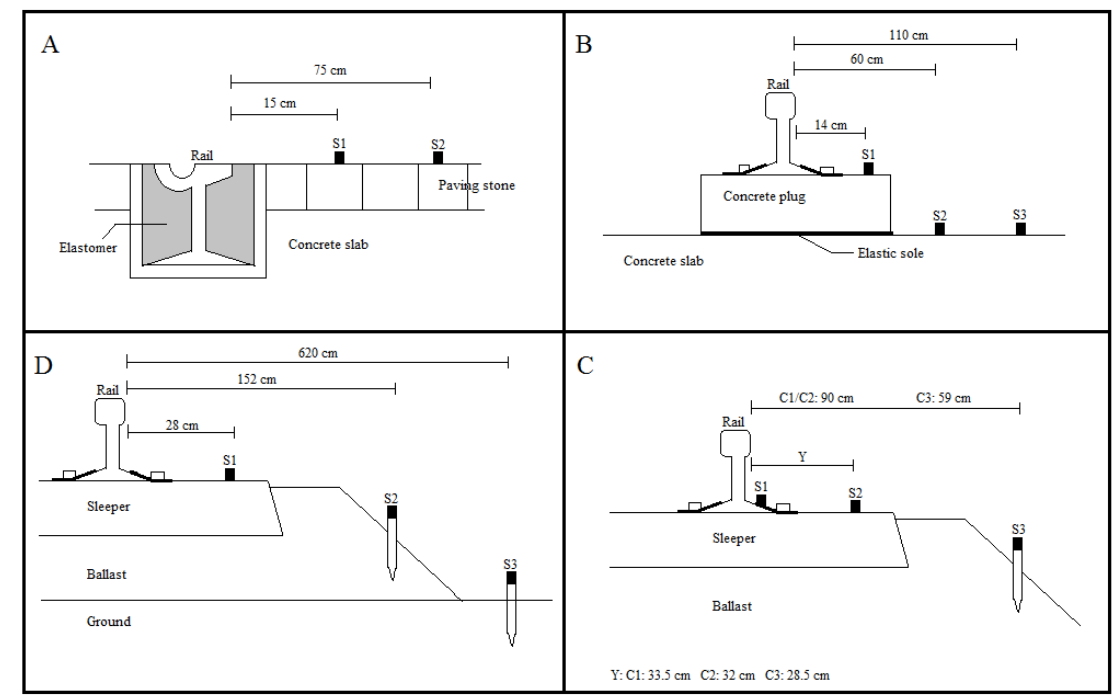

Note: S indicates Sensor location.

Figure 1. Sensors location scheme. Clockwise starting from top left: Section A, Section B, Section C, Section D. 

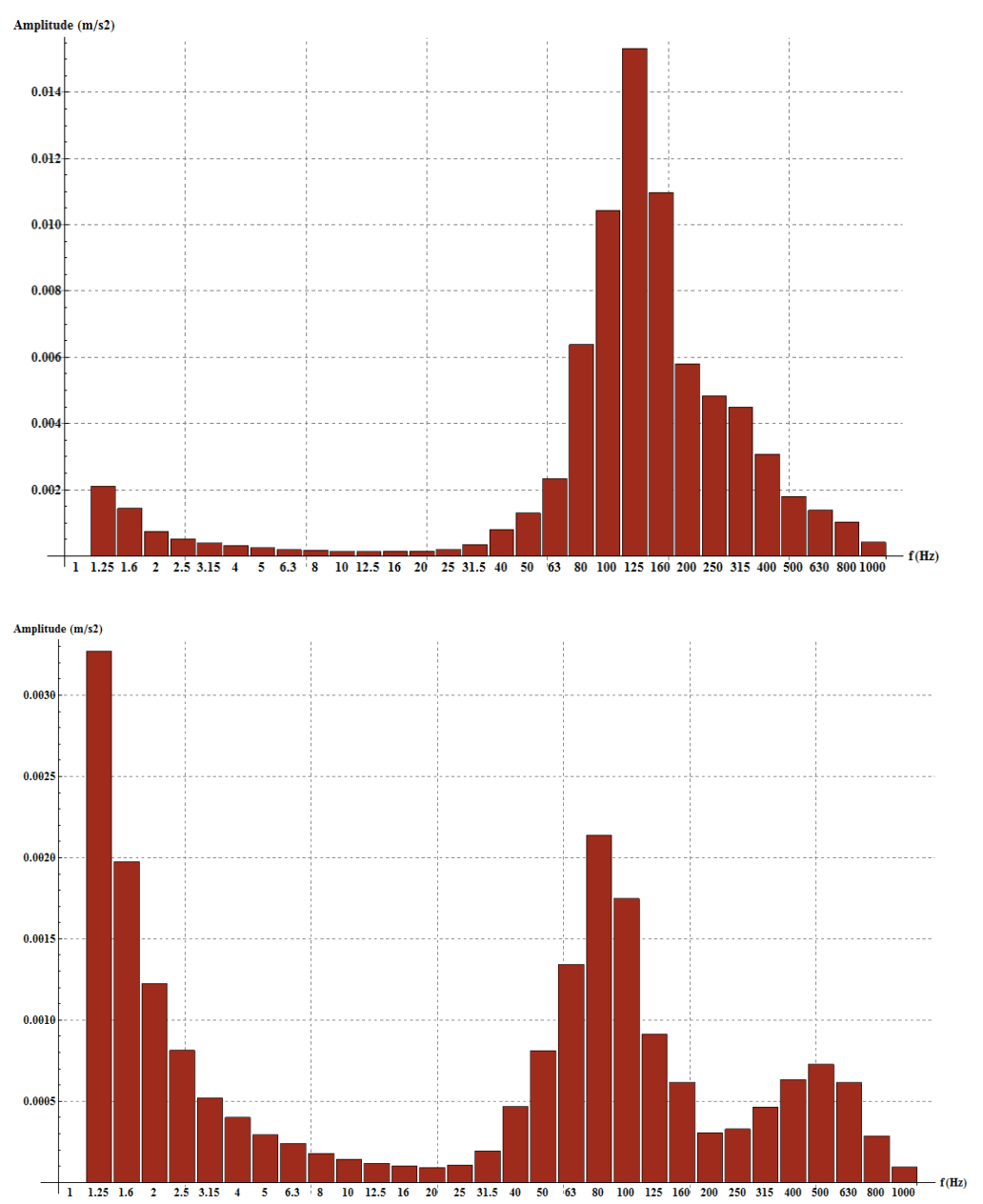

Figure 2. Average 1/3 Octave spectrum in section A; (top) $15 \mathrm{~cm}$ from rail (S1). (bottom) $75 \mathrm{~cm}$ from rail (S2). 


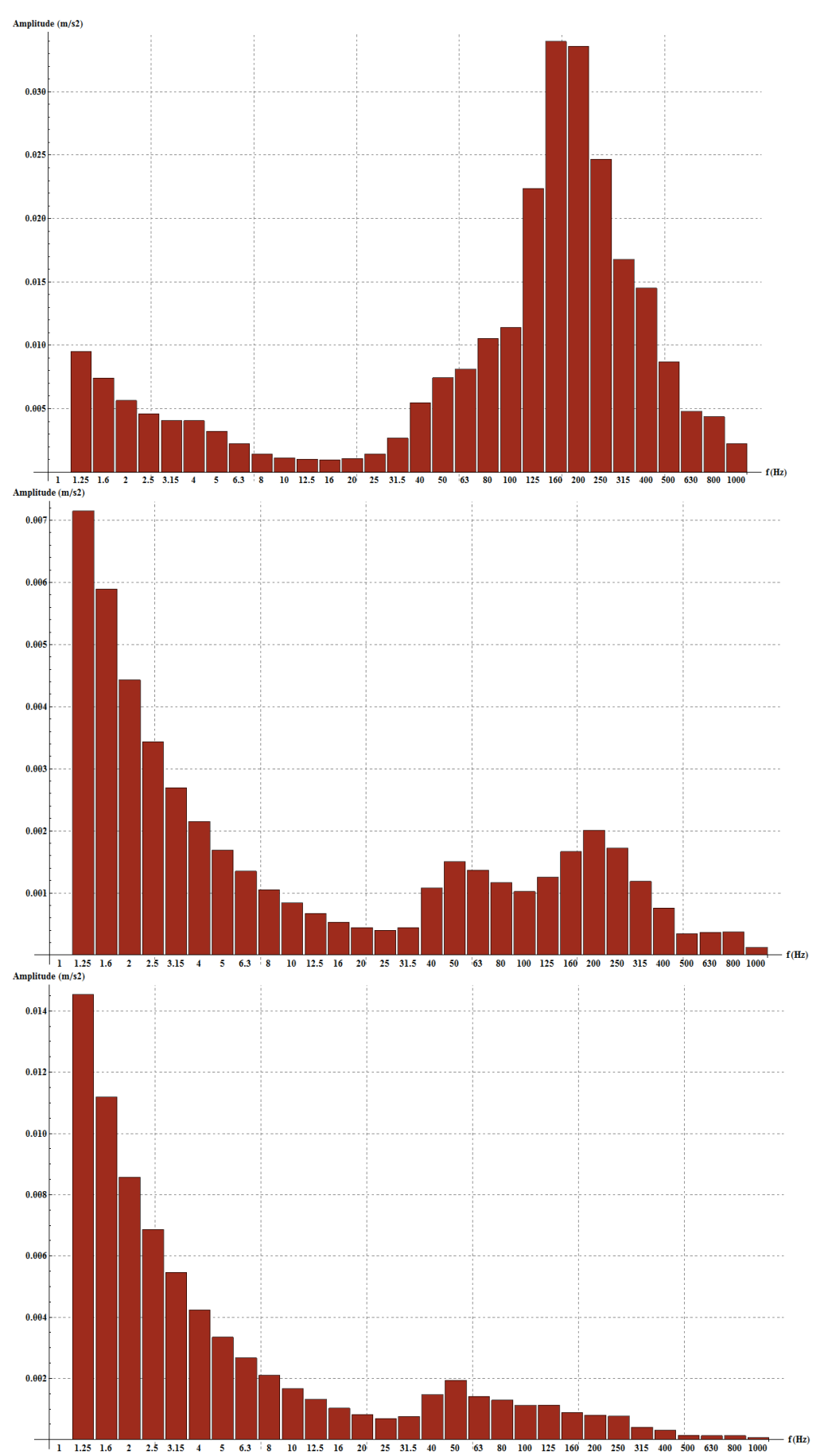

Figure 3. Average 1/3 Octave spectrum in section B; (top) sleeper (S1), (middle) slab, 60 $\mathrm{cm}$ from rail (S2), and (bottom) slab, $110 \mathrm{~cm}$ from rail (S3). 


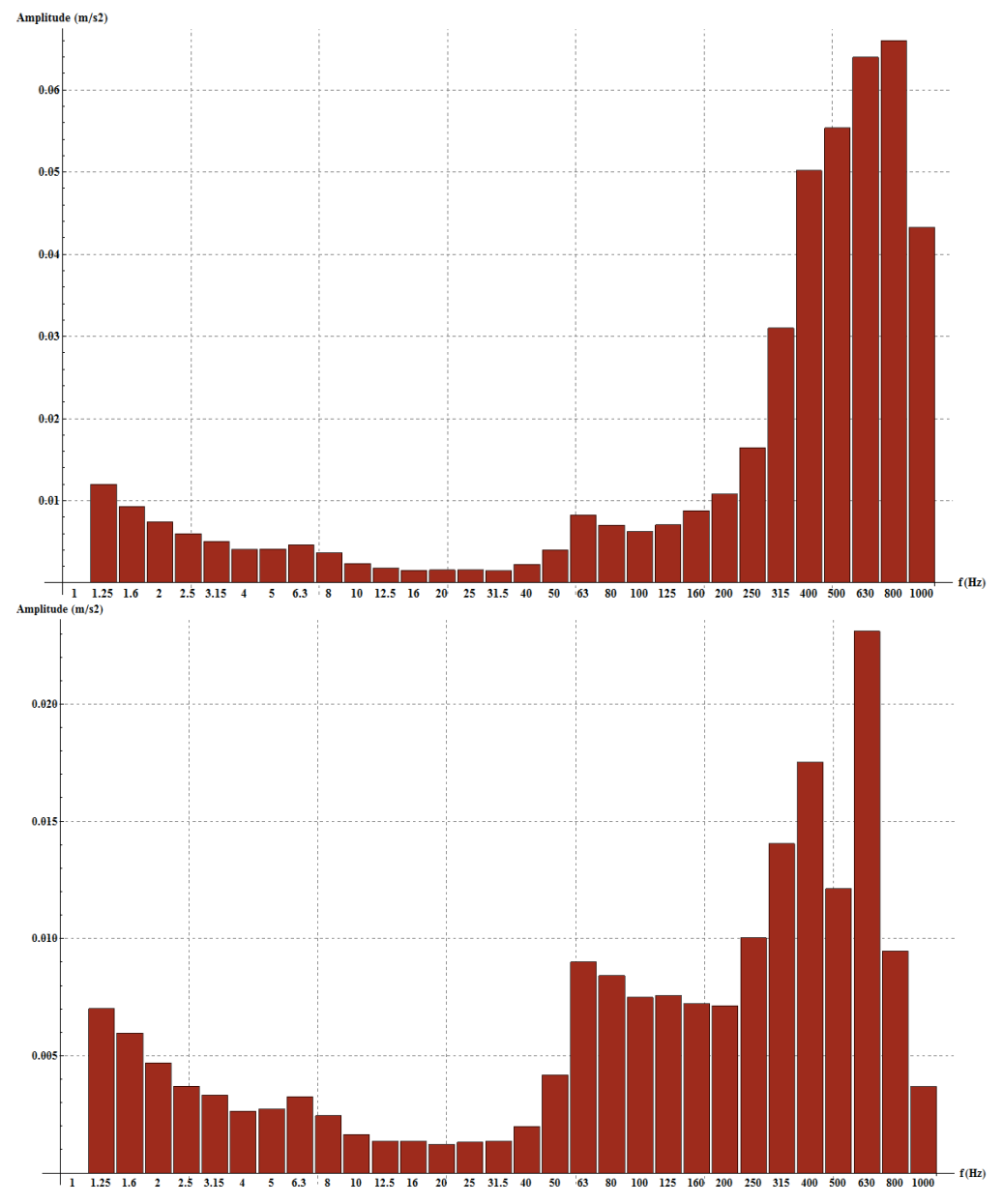

Figure 4. Average 1/3 Octave spectrum in section C1; (top) rail (S1) and (bottom) sleeper (S2). 


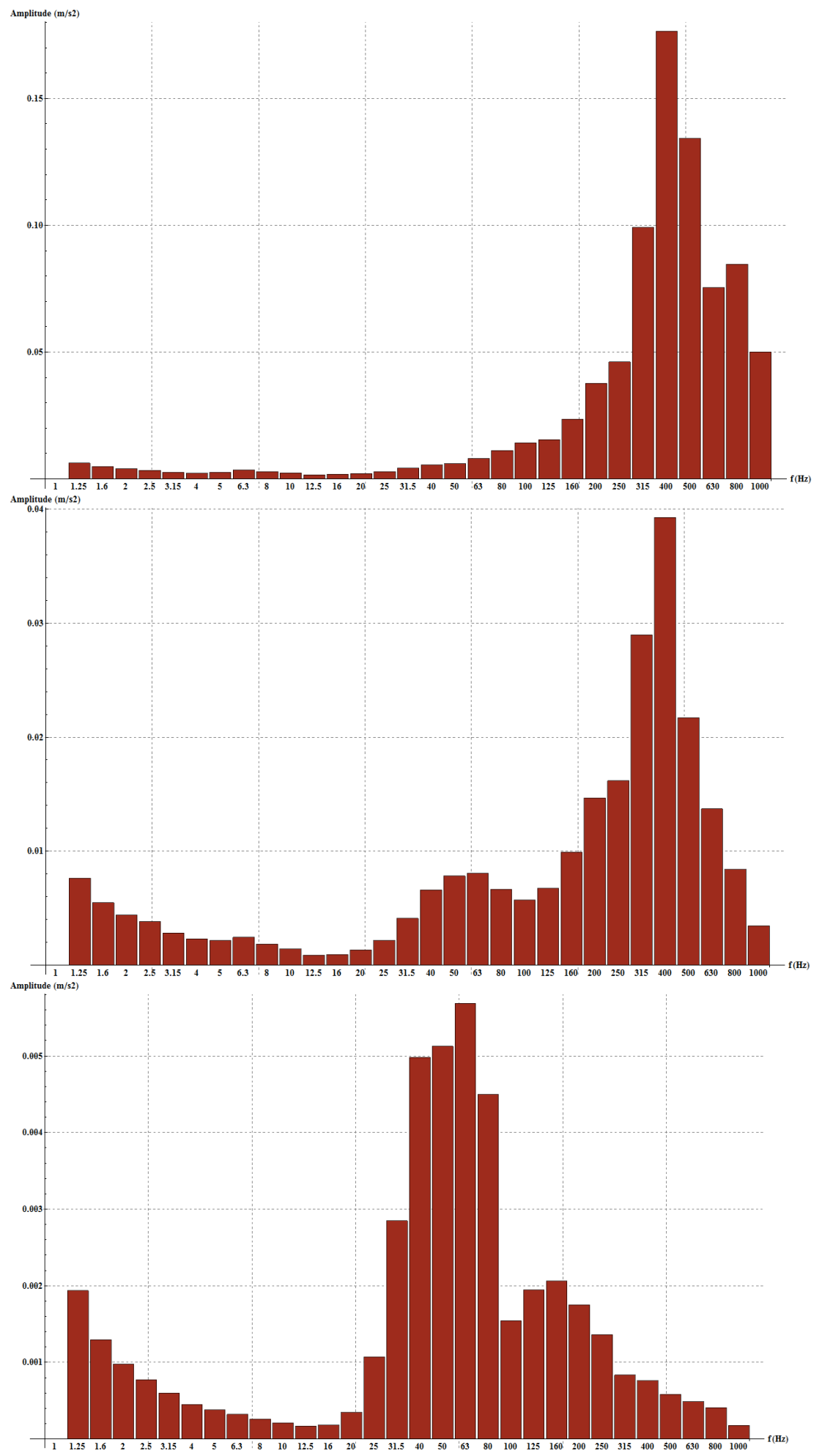

Figure 5. Average 1/3 Octave spectrum in section C2; (top) rail (S1), (middle) sleeper (S2), and (bottom) ballast (S3). 


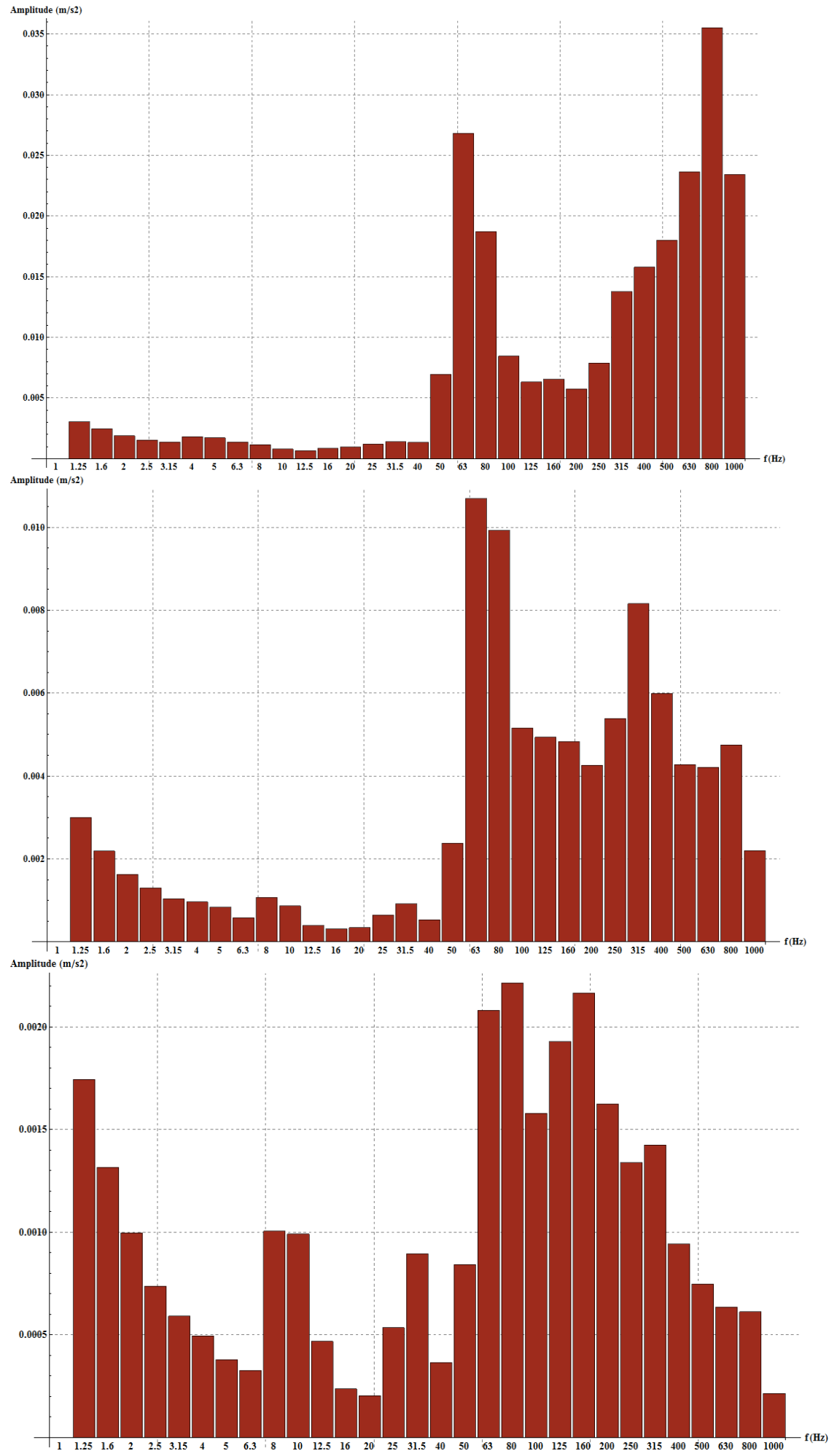

Figure 6. Average 1/3 Octave spectrum in section C3; (top) rail (S1), (middle) sleeper (S2) and (bottom) Ballast (S3). 


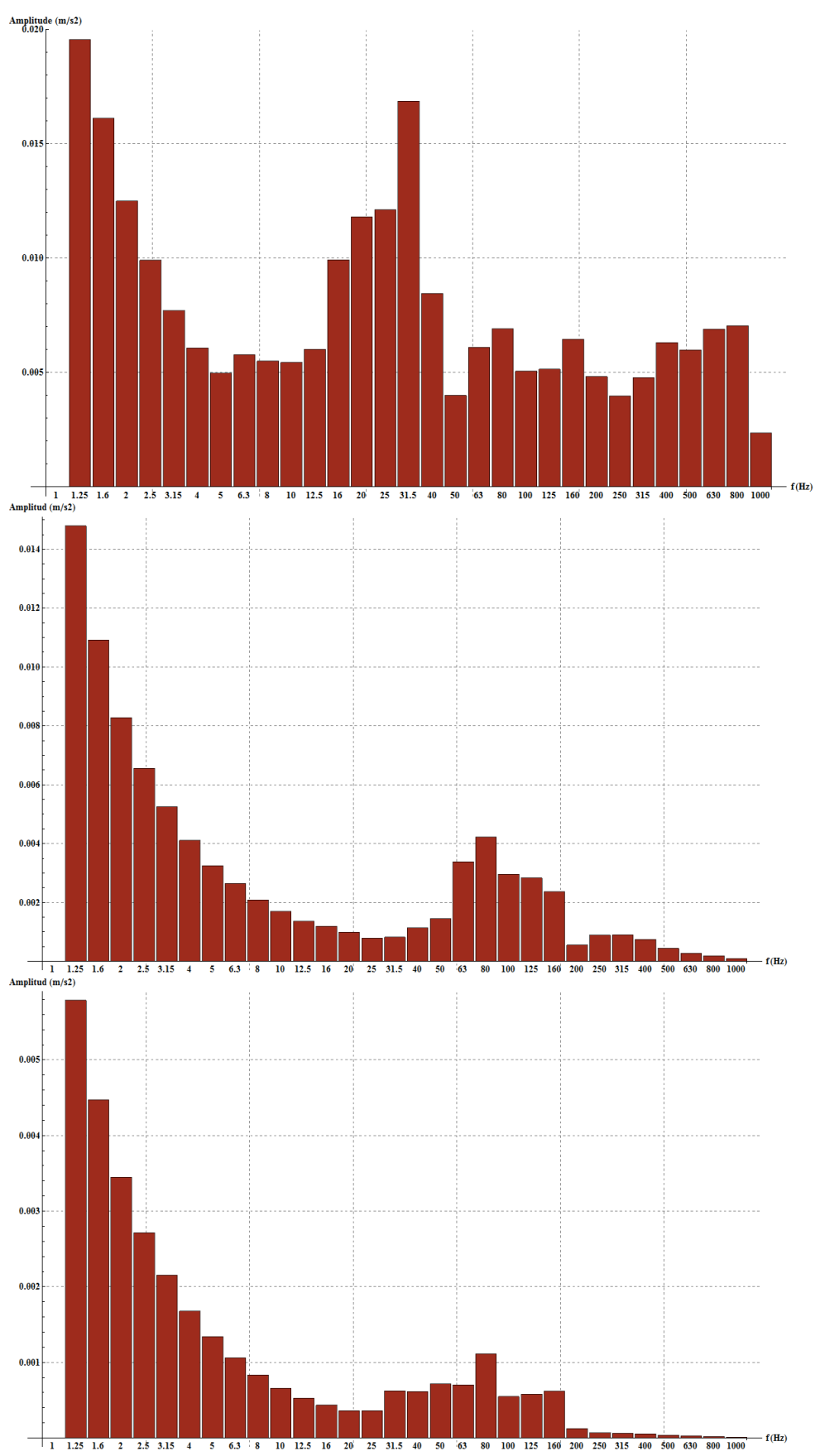

Figure 7. Average 1/3 Octave spectrum in section D; (top) sleeper (S1), (middle) ballast (S2), and (bottom) ground (S3). 


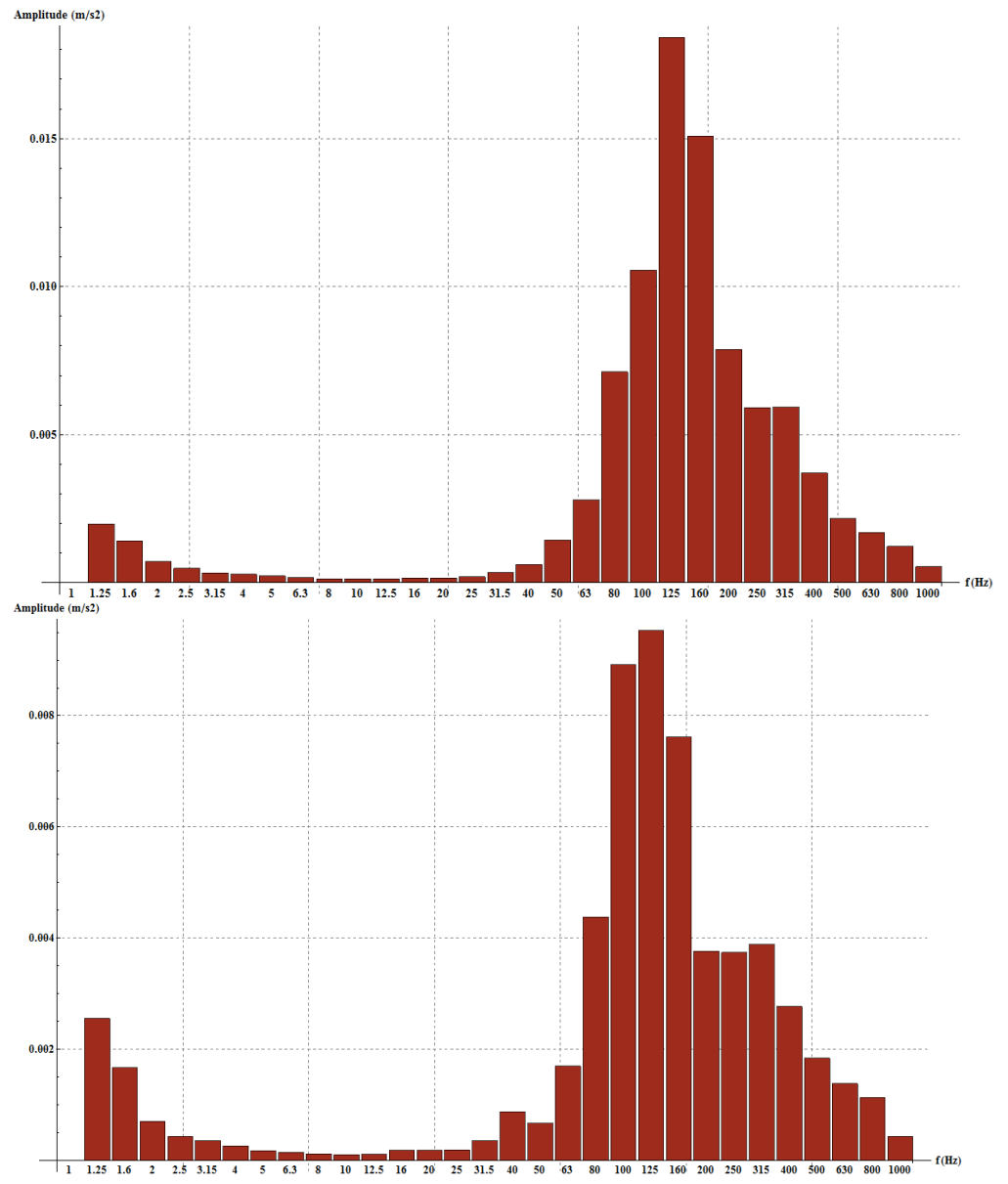

Figure 8. Average 1/3 Octave spectrum in section A (S1); (top) 3800 series, and (bottom) 4200 series. 


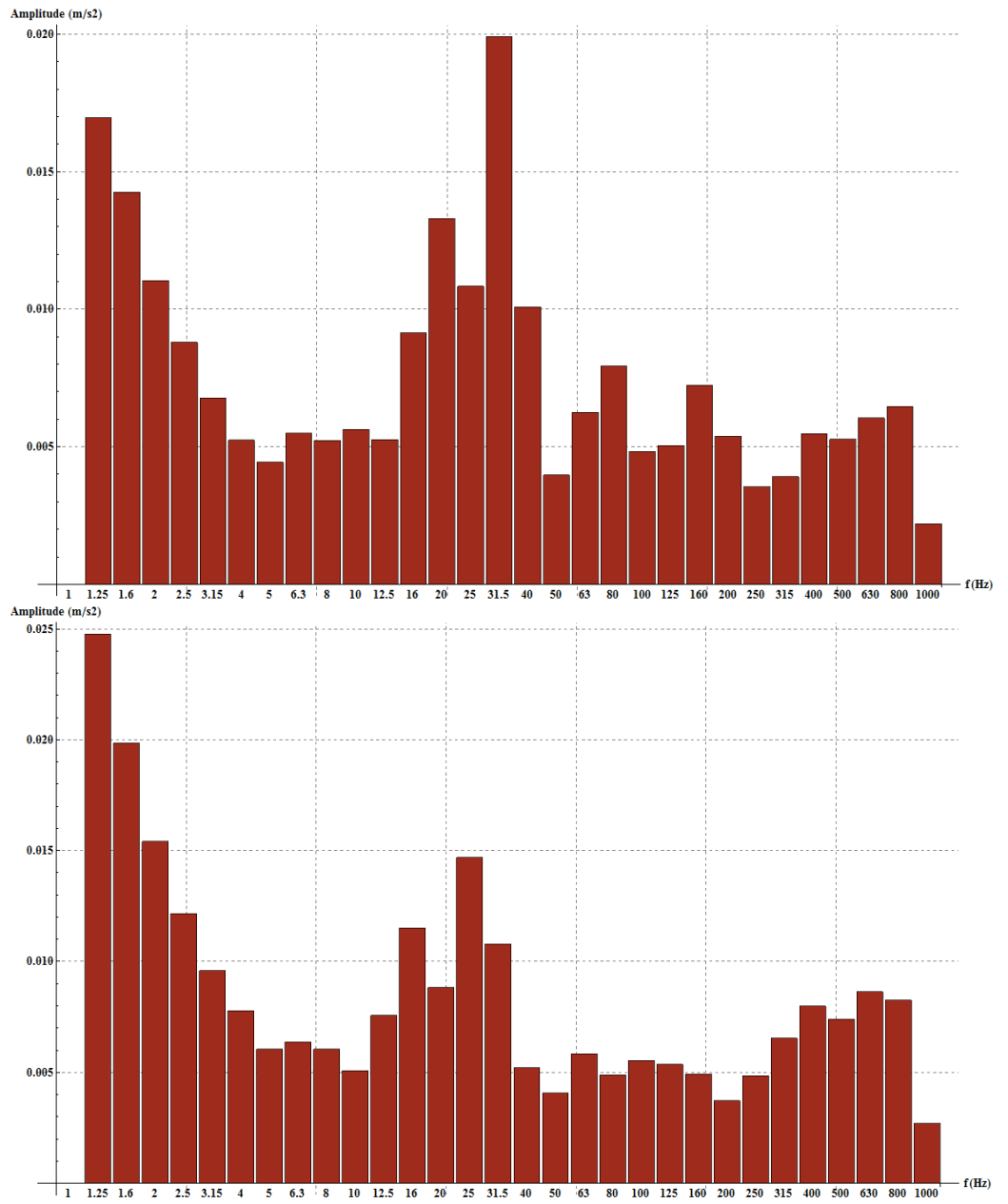

Figure 9. Average 1/3 Octave spectrum in section D (S1); (top) AVE series and (bottom) ALVIA series. 